\title{
OURICÚRI
}

\section{GERMINAÇÃO E MODIFICAÇÕES ANATÔMICAS EM SEMENTES DE Sesbania virgata (CAV.) PERS. SUBMETIDAS À ESCARIFICAÇÃO QUÍMICA}

Saymon Acchile SANTOS ${ }^{1 *}$; Renato Nunes COSTA $^{2}$; Jania Claudia Camilo dos SANTOS ${ }^{2}$; Dayane Mércia Ribeiro SILVA ${ }^{2}$; Lennon Kledson dos Santos SILVA ${ }^{1}$; Jessé Marques da Silva Júnior PAVÃO3; Flávia de Barros Prado MOURA ${ }^{3}$; José Vieira SILVA ${ }^{3}$

1 Universidade Federal de Alagoas. Centro de Ciências Agrárias, BR 104, Rio Largo - AL, CEP: 57072-900. E-mail: kledson.lennon@hotmail.com. *Autor correspondente. E-mail: saymonufal@gmail.com; 2Universidade Estadual Paulista, Botucatu - SP, CEP: 18610-307. E-mail: renatonunes12@hotmail.com; janya-claudia@hotmail.com, dayannemercia@hotmail.com.

3 Universidade Federal de Alagoas. Av. Manoel Severino Barbosa, Bom Sucesso, Arapiraca - AL, CEP: 57309-005. E-mail: jesseagronomo@yahoo.com.br; fbpm@mhn.ufal.br; vieira@arapiraca.ufal.br.

Recebido: 16.02.2019 Aceito: 06.06.2019

http://doi.org/10.29327/ouricuri.v9.i1.a1

Resumo: Este trabalho teve como objetivo avaliar os efeitos da aplicação do ácido sulfúrico concentrado na germinação e possíveis alterações anatômicas tegumentar na superação de dormência das sementes de Sesbania virgata (Cav.) Pers. Para isto, foram utilizados oito diferentes tempos de exposição das sementes ao ácido sulfúrico (0,15, 30, 45, 60, 120, 180 e 240 minutos), avaliando a porcentagem de germinação, índice de velocidade e o tempo médio de germinação. Além disso, para cada tempo de exposição, foi avaliado as alterações anatômicas das sementes. Foi possível descrever quatro diferentes estratos do tegumento (cutícula cerosa, camada de células paliçadas, osteosclereides e uma camada de células parenquimáticas). Os resultados sugerem que a aplicação do ácido sulfúrico de até 60 minutos é recomendada para superar a dormência de sementes de $S$. virgata, uma vez que aumenta a porcentagem de germinação e origina plântulas normais. Constatou-se também que a exposição das sementes de $S$. virgata ao ácido sulfúrico em períodos iguais ou superiores a 120 minutos, promove a geração de novas plântulas anormais, além de desestruturar os estratos do tegumento e causar danos diretos a camada de aleurona e endosperma.

Palavras-chave: Tegumento; Anatomia; Espécie Florestal.

\section{GERMINATION AND ANATOMICAL ANALYSIS OF Sesbania virgata (CAV.) PERS. SEED COAT UNDER CHEMICAL SCARIFACTION}

\begin{abstract}
This study aimed to evaluate the effects of the application of concentrated sulfuric acid on germination and possible tegumentary anatomical alterations in the overcoming of dormancy of the seeds of Sesbania virgata (Cav.) Pers. For this purpose were used eight different immersion periods $(0,15,30,45,60,120,180$ and $240 \mathrm{~min})$, assessing the percentage of germination, speed index and average germination time. In addition, for each exposure time, it was evaluated the anatomic changes of the seeds. It was possible to describe four different strata (cuticle waxy layer of palisade cells, osteoesclereídes and a layer of parenchyma cells). The results suggest that the sulfuric acid application of up to 60 minutes is recommended to overcome seed dormancy of $S$. virgata, since it increases the germination percentage and gives rise to normal seedlings. In addition, it was verified that the exposure of S. virgata seeds to sulfuric acid in periods equal to or greater than 120 minutes, promotes the generation of new abnormal seedlings, as well as to disintegrate the layers of the integument and cause direct damage to the aleurone layer and endosperm.
\end{abstract}

Revista Ouricuri, Juazeiro, Bahia, v.9, n.1. p.001-012. jan./jun., 2019.

http://www.revistas.uneb.br/index.php/ouricuri | ISSN 2317-0131 
Keywords: Coat; Anatomy; Forest Species.

\section{Germinación y modificaciones anatómicas em semillas de Sesbania virgata (CAV.) PERS. sometidas a escarificación química}

Resumen: Este trabajo tuvo como objetivo evaluar los efectos de la aplicación de ácido sulfúrico concentrado en la germinación y posibles alteraciones anatómicas tegumentales en la superación de la dormencia de semillas de Sesbania virgata (Cav.) Pers. Para ello, fueron utilizados 8 tiempos de exposición diferentes de las semillas al ácido sulfúrico $(0,15,30,45,60,120,180$ y 240 minutos), evaluando el porcentaje de germinación, índice de velocidad y el tiempo medio de germinación. Además, para cada tiempo de exposición, fueron evaluadas las alteraciones anatómicas de las semillas. Fue posible describir cuatro diferentes estratos del tegumento (cutícula cerosa, capa de células empalizadas, osteosclereideos y una capa de células parenquimáticas). Los resultados sugieren que la aplicación del ácido sulfúrico hasta los 60 minutos es recomendada para superar la dormencia de las semillas de S. virgata, dado que aumenta el porcentaje de germinación y origina plántulas normales. También fue constatado que la exposición de las semillas de S.virgata al ácido sulfúrico en períodos iguales o superiores a 120 minutos promueve la generación de nuevas plántulas anormales, aparte de desestructurar los estratos del tegumento y causar daños directos a la capa de la aleurona y el endosperma.

Palabras clave: Tegumento, Anatomía, Especie forestal.

\section{INTRODUÇÃO}

A Sesbania virgata (Cav.) Pers. é uma espécie arbustiva, pertencente à família Fabaceae, nativa do Brasil, com ocorrência nas regiões Centro-oeste, Nordeste, Sudeste e Sul, abrangendo os biomas Caatinga, Cerrado, Mata Atlântica, Pampa e Pantanal (IGANCl e MIOTTO, 2016). Apresenta elevado potencial na utilização em programas de reflorestamento, recuperação de áreas degradadas e adubação verde (FLORETINO e MOREIRA, 2009). A capacidade de realizar simbiose radicular auxilia na absorção de nutrientes em solos de baixa fertilidade (DELARMELINA et al., 2014).

A exploração desta espécie é limitada, principalmente pelo estado de dormência apresentada pelas sementes, em que, mesmo em condições ideais de temperatura, umidade, oxigênio e luz, não há germinação ou esta ocorre de forma tardia e desuniforme. Nas espécies deste gênero, a dormência ocorre em níveis diferenciados e relacionam-se ao impedimento da entrada de água e/ou gases ao embrião; ou ainda são ocasionadas por substâncias inibidoras da germinação como suberina, lignina, cutina e mucilagens, na testa, pericarpo ou membrana nuclear, comum em espécies de leguminosa (BEWLEY, 1997).

Métodos de escarificações de sementes são ferramentas ideais para que a semente dormente manifeste seu potencial germinativo. De acordo com Wang et al. (2012), o ácido sulfúrico é uma ferramenta de sucesso por permitir viabilizar processos bioquímicos e fisiológico de germinação de sementes. Para mais, compõe uma ferramenta rápida e eficiente, além de mostrar ser uma alternativa de sucesso para a utilização em larga escala para diversas espécies florestais, pertencentes a esta família, tais como Bauhinia forficata (COSTA et al., 2013) e Samanea tubulosa

Revista Ouricuri, Juazeiro, Bahia, v.9, n.1. p.001-012. jan./jun., 2019.

http://www.revistas.uneb.br/index.php/ouricuri | ISSN 2317-0131 
(OLIVEIRA et al., 2012). A eficiência e sucesso dessa técnica, no entanto, pode ser questionável, pois depende de características intrínsecas da semente e, diretamente, do tempo de exposição desta ao ácido sulfúrico. A depender do período de exposição, a utilização deste ácido pode gerar efeitos deletérios excessivos no tegumento (OLIVEIRA et al., 2012), causando deterioração da semente, levando a danos físicos, fisiológicos e elevando o número de plântulas anormais e/ou sementes mortas.

Investigações que avaliem de alguma forma, os possíveis danos anatômicos que a escarificação química pode acarretar às sementes, são raramente encontradas na literatura. Dessa forma, este trabalho teve como objetivo avaliar os efeitos da aplicação do ácido sulfúrico concentrado na germinação e possíveis alterações anatômicas tegumentar na superação de dormência das sementes de $S$. virgata.

\section{MATERIAL E MÉTODOS}

Os frutos de $S$. virgata foram coletados no ponto de maturidade fisiológica das sementes em 20 árvores matrizes adultas distanciadas por no mínimo 50 metros, na cidade de Arapiraca-AL - 264 m de altitude, latitude $9^{\circ} 41^{\prime} 53,6^{\prime \prime}$ S; longitude 3641'26,3" W e clima Tipo 'As' pela classificação de Köppen, durante os meses de setembro a dezembro de 2015. Todas as análises experimentais foram realizadas no Laboratório de Fisiologia Vegetal da Universidade Federal de Alagoas Campus Arapiraca, logo após a colheita dos frutos.

O teste para superação de dormência foi conduzido em delineamento inteiramente casualizado (DIC), com oito tratamentos e quatro repetições compostas de 30 sementes. Os tratamentos pré-germinativos empregados para superação da dormência das sementes foram, além do controle, constituídos por sementes que não receberam tratamento algum, a imersão das sementes em ácido sulfúrico $\left(\mathrm{H}_{2} \mathrm{SO}_{4}\right)$ concentrado (98\%) durante: 15, 30, 45, 60, 120, 180, 240 minutos, totalizando oito tratamentos. As sementes, referentes ao tratamento controle, foram desinfestadas em solução de hipoclorito de sódio (2,4\%) por três minutos e, em seguida, lavadas em água destilada para remoção de possíveis resíduos do hipoclorito como tratamento prégerminativo.

As sementes foram semeadas em caixas tipo "gerbox", transparente, utilizando como substrato papel mata-borrão umedecido com água destilada, na proporção equivalente a 2,5 vezes o peso do substrato não hidratado, sendo colocadas em câmara de germinação do tipo B.O.D (Biochemical Oxigen Demand), ajustada a temperatura de $25^{\circ} \mathrm{C} \pm 1^{\circ} \mathrm{C}$ e sob luz constante.

A avaliação da germinação foi realizada por meio da contagem diária das sementes germinadas até a sua estabilização, que ocorreu no $18^{\circ}$ dia. Avaliações diárias foram feitas tendo como critérios de germinação: sementes que apresentaram o crescimento da radícula $\geq 2 \mathrm{~mm}$, como também o surgimento de plântulas normais. Na condução do teste de germinação avaliou-se a 
porcentagem de germinação (\%G); o índice de velocidade de germinação (IVG) e tempo médio de germinação (TMG) (LABOURIAU, 1983).

Os resultados obtidos foram submetidos à análise de variância e, quando significativos, as médias foram ajustadas em regressão polinomial, com o auxílio do programa estatístico SISVAR, versão 5.6 Build 86 (FERREIRA, 2014).

Para a observação da ação do ácido sulfúrico $\left(\mathrm{H}_{2} \mathrm{SO}_{4}\right)$ nos tecidos do tegumento, 160 sementes de $S$. virgata foram submetidas aos mesmos tratamentos utilizadas para superação da dormência em tempos de exposição ao ácido de 0,15, 30, 45, 60, 120, 180 e 240 minutos. O delineamento foi o DIC com oito tratamentos e quatro repetições, sendo cada unidade experimental composta por cinco sementes.

Para os cortes, as sementes foram coletadas e fixadas em $\mathrm{FAA}_{70 \%}$ (formaldeído, ácido acético e etanol) por 48 horas e, posteriormente, conservadas em etanol 70\% (JOHANSEN, 1940). Os cortes transversais foram realizados à mão livre com auxílio de lâminas de gilete.

As lâminas foram montadas usando-se em água glicerinada (50\% de $\mathrm{H}_{2} \mathrm{O}+50 \%$ glicerina) e foram seladas com esmalte incolor. Posteriormente, foram observadas em microscópio óptico (Modelo NOVA 107, Nova Optical System, Brasil) utilizando à objetiva $\mathrm{n}^{\circ} 10$ e fotografadas com câmera Canon A480 aumentada quatro vezes, acoplada ao microscópio óptico.

\section{RESULTADOS}

O processo germinativo das sementes de $S$. virgata foi influenciado pelos diferentes tempos de exposição em ácido sulfúrico, ao afetar significativamente as variáveis porcentagem de germinação (\%G), índice de velocidade de germinação (IVG) e tempo médio de germinação (TMG). Neste sentido, houve efeito significativo para a equação de segundo grau, havendo ajuste quadrático (Tabela 1 e Figura 1).

Tabela 1. Resumo da análise de variância das variáveis porcentagem de germinação $(\% G)$, índice de velocidade de germinação (IVG), tempo médio de germinação (TMG), obtidos em sementes de Sesbania virgata (Cav.) Pers. submetidas a diferentes períodos de imersão em ácido sulfúrico.

\begin{tabular}{|c|c|c|c|c|}
\hline \multirow{2}{*}{ Fonte de variação } & \multirow{2}{*}{$\mathrm{GL}$} & \multicolumn{3}{|c|}{ Quadrado Médio } \\
\hline & & $\% G$ & IVG & TMG \\
\hline Tratamento & 7 & 4840,29 * & $67,98^{*}$ & $4,11^{*}$ \\
\hline Regressão Linear & 1 & $2008.893^{* *}$ & $27.605^{\star \star}$ & $5.256^{\star \star}$ \\
\hline Regressão Quadrado & 1 & $20743.923^{\star *}$ & $333.153^{* *}$ & $10.765^{\star *}$ \\
\hline Desvio de Regressão & 5 & 2225.836 & 23.017 & 2.551 \\
\hline Resíduo & 24 & 22,58 & 0,43 & 0,15 \\
\hline CV (\%) & & 6,79 & 8,51 & 13,35 \\
\hline
\end{tabular}

**, * Significativo, respectivamente, a 1 e $5 \%$ de probabilidade de probabilidade pelo teste $\mathrm{F}$. 
A partir da regressão polinomial foi observado acréscimo na percentagem de germinação com o aumento do tempo de exposição ao ácido sulfúrico até os 128 minutos (Figura 1A). Este último, caracterizado como o ponto máximo da germinação, estabelecendo com isso $100 \%$ de sementes germinadas. Após o ponto máximo tem-se uma redução na germinação das sementes de $42 \%$ quando submetidas a 240 minutos de exposição ao ácido.

No que se refere ao vigor das sementes por meio da variável IVG, observou-se incrementos positivos até o tempo de exposição de 137 minutos, proporcionando índice de velocidade de germinação de 13,8 (Figura 1B), após esse tempo o índice reduziu até 5,8 aos 240 minutos, o que representa uma redução de $42 \%$.

Por meio da derivada da equação, o menor TMG (1,5 dias) é observado aos 162 minutos de exposição das sementes ao ácido sulfúrico (Figura 1C). No entanto, longos períodos de imersão (acima de 120 minutos) promoveram germinação com dano devido uma maior velocidade na absorção de água ocasionada pela deterioração do tegumento, além de ter afetado o desenvolvimento normal do processo germinativo das sementes.

A depender do tempo de imersão das sementes ao ácido, a embebição poderá ou não ocasionar uma germinação com plântulas normais. Assim, a utilização do ácido por 30, 45 e 60 minutos, pode promover o desgaste do tegumento, entretanto sem comprometer a integridade dos tecidos preponderantes à germinação e geração de novas plântulas, promovendo com isto alta porcentagem de germinação (Figuras 2B, C, D e E). Já a imersão em períodos prolongados (120, 180 e $240 \mathrm{~min}$ ) comprometeu as estruturas internas da semente, prejudicando o processo germinativo (Figuras $2 \mathrm{~F}, \mathrm{G}$ e H). 

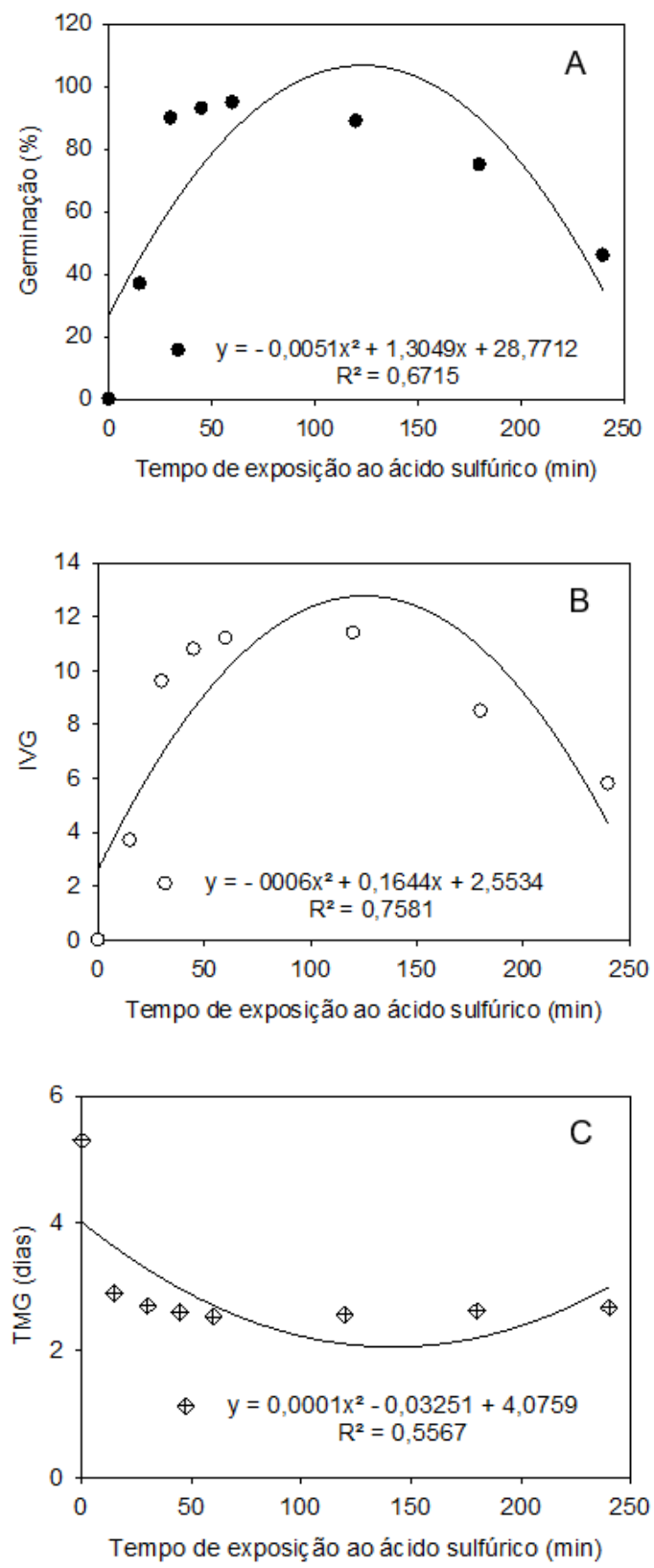

Figura 1. Porcentagem de germinação (G\%) (A), índice de velocidade de germinação (IVG) (B) e tempo médio de germinação (TMG) (C) de Sesbania virgata (Cav.) Pers. em função da exposição ao ácido sulfúrico. 

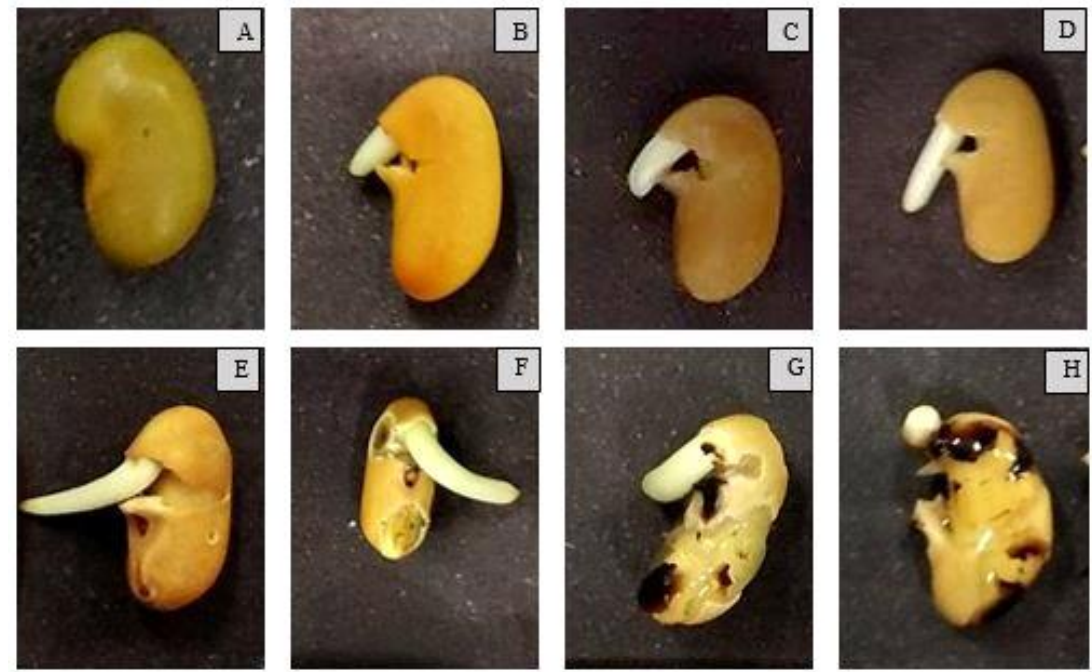

Figura 2. Sementes de Sesbania virgata (Cav.) Pers. submetidas a diferentes tempos de imersão em ácido sulfúrico: $0(A), 15(B), 30(C), 45(D), 60(E), 120(F), 180(G)$ e 240 minutos $(H)$.

$\mathrm{Na}$ descrição estrutural do tegumento verificam-se quatro diferentes estratos presentes nas sementes de $S$. virgata, sendo eles: cutícula cerosa; camada de células paliçadas - formadas por macroesclereídes alongadas no sentido radial; uma camada de células ampulheta em formato alongado - chamadas de células em pilar, hourglass ou osteoesclereídes; e uma camada de células parenquimáticas, encontrando-se parcialmente e/ou completamente condensados (Figura 3).

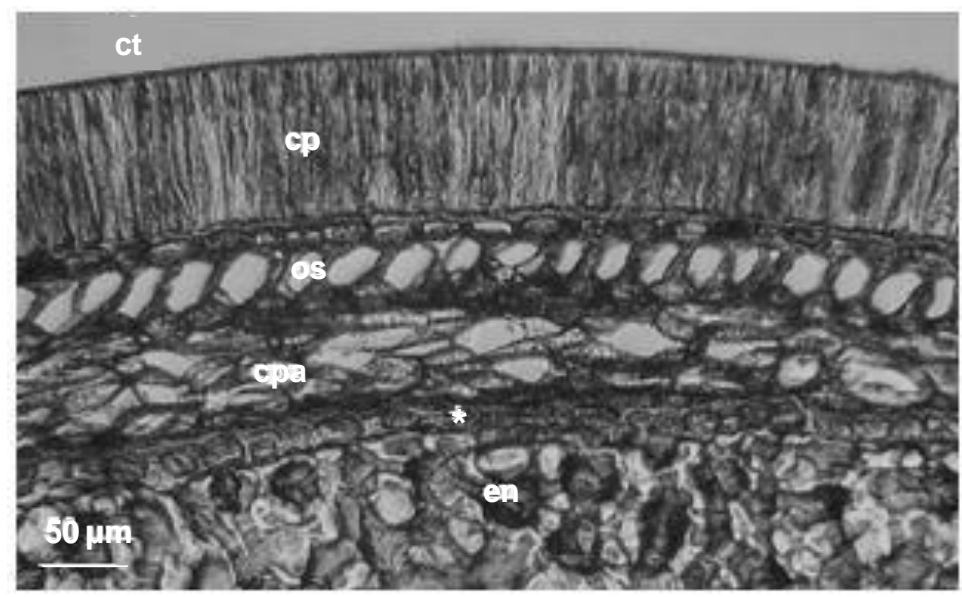

Figura 3. Secções transversais do tegumento de sementes de Sesbania virgata (Cav.) Pers. analisadas por microscopia óptica. Onde: ct (cutícula), cp (células paliçádicas), os (osteosclereídes), cpa (células parenquimáticas), *camada de aleurona e en (endosperma).

O ácido sulfúrico concentrado como ferramenta de superação de dormência, produziu danos físicos, os quais, a depender do período de exposição, causaram injúrias irreversíveis à germinação das sementes de $S$. virgata. No tratamento com ácido durante 45 minutos, pode-se observar que a maior parte da superfície mais externa da semente, camada cuticular, tem aparência enrugada e espessura depreciada. É possível observar ainda o início da degradação destas primeiras camadas de células protetoras, causadas pela ação corrosiva do ácido sulfúrico (Figura 4D). 
À medida que o tempo de imersão foi aumentando, a partir de 60 minutos, fica evidente a ação abrasiva do ácido sobre os tecidos mais internos do tegumento, refletindo na degradação parcial da camada paliçádica e produção de fissuras ao longo dos tecidos do tegumento (Figura 4E). Na exposição das sementes de $S$. virgata durante 120 minutos, evidenciou-se a desestruturação de todas as camadas do tegumento, ficando impossibilitada a identificação de seus respectivos estratos (Figuras 4F). Já a exposição a tempos superiores (180 e 240 minutos) foi verificado a remoção total do tegumento e produção de danos diretos ao endosperma e, consequente, morte do embrião (Figura 4G e H).
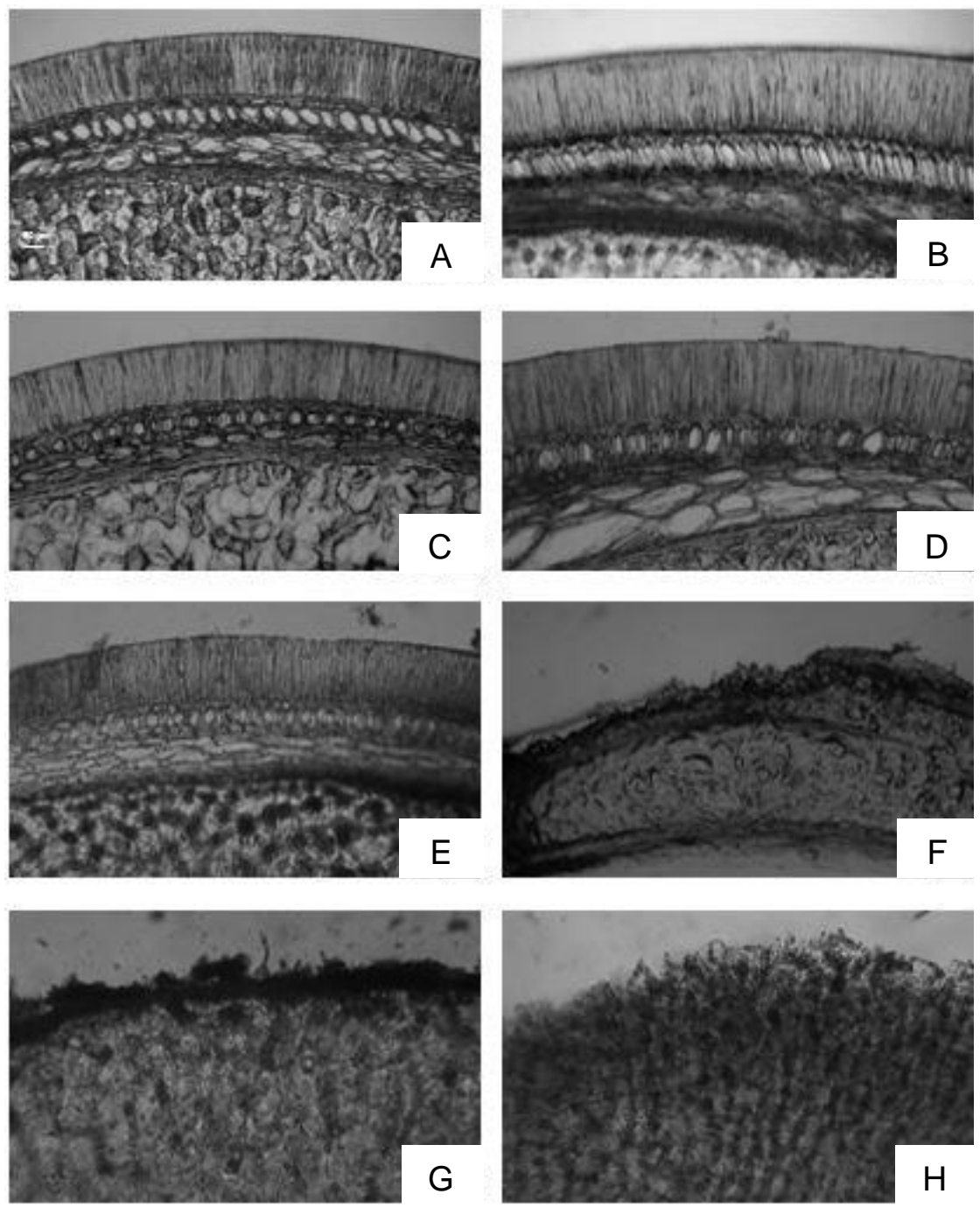

Figura 4. Secções transversais do tegumento de sementes de Sesbania virgata (Cav.) Pers. analisadas por microscopia óptica. Tempos de imersão: 0 (A), 15 (B), 30 (C), 45 (D), 60 (E), 120 $(F), 180(G)$ e 240 minutos $(H)$.

\section{DISCUSSÃO}

Os efeitos observados sobre a germinação de sementes de $S$. virgata, provavelmente, estão associados à ação corrosiva do ácido concentrado, assim como verificados no trabalho de Dousseau et al. (2007), onde o ácido sulfúrico a 98\% promoveu efeitos negativos sobre a

Revista Ouricuri, Juazeiro, Bahia, v.9, n.1. p.001-012. jan./jun., 2019. 
germinabilidade de sementes de Fabaceae, reduzindo-a em aproximadamente $90 \%$ em relação ao tratamento de maior eficácia.

Além dos índices de germinação, o vigor das sementes de Fabaceae também pode ser influenciado pela presença de ácido sulfúrico (Lima et al., 2014). Costa et al. (2013) constataram que sementes de Bauhinia forficata quando imersas em ácido sulfúrico por 5, 10 e 15 minutos, obtiveram maiores índices de velocidade de germinação e menores tempos médios de germinação. Em sementes de Chloroleucon foliolosum a escarificação com ácido sulfúrico por 15 ou 30 minutos também foi eficiente para superação da dormência, ao aumentar a porcentagem de germinação e o índice de velocidade de germinação (Silva et al., 2014). Em adição, Montoan et al. (2012) verificaram que quando as sementes de Adenanthera pavonina L. são expostas ao ácido sulfúrico por 30 minutos aumentaram a porcentagem de germinação em $65 \%$, enquanto que, aos 40 minutos, a germinação diminuiu (53\%) e aumentou o nível de sementes deterioradas.

A partir das características anatômicas gerais observadas no tegumento das sementes de S. virgata, é possível concluir que estas, de acordo com a classificação de Corner (1976), se enquadram como sementes exotestais; caracterizadas por possuírem camadas de células mecânicas predominantemente face mais externa da testa. Sementes desse tipo são bastante comuns em espécies de Fabaceae como pode ser visto nos estudos com morfoanatomia de sementes de Adesmia tristes (Ferreira et al., 2011) e Amburana cearenses (Loureiro et al., 2013).

Em espécies como $S$. virgata, a camada cuticular espessa auxilia na proteção e impermeabilidade do tegumento representando a primeira barreira à embebição. Logo após as células da cutícula um conjunto de células formadas por macroesclereídes, conhecidas por camada paliçádica, que funcionam como uma barreira impermeável que impede a absorção de água por conta de seu arranjo físico e por seus revestimentos químicos - lignina, cutina, suberina, ceras; e que de acordo com Abreu et al. (2012) se trata de um tecido bastante característico de sementes da família Fabaceae.

Adjacente às células paliçádicas, encontra-se um grupo de células subepidérmicas alongadas, com as extremidades alargadas que lembram a forma de um osso e denominam-se osteosclereides. Geralmente nestas células há a ocorrência de uma dupla camada de osteoesclereídes, uma vez que estas são comuns em sementes de leguminosas; como também uma camada externa e uma mais interna, que formam uma barreira dupla para a entrada de água e oxigênio na semente (Ferreira et al.,2011). Entretanto, nas sementes de S. virgata não foram evidenciadas tais camadas. O último e mais interno estrato encontrado foi uma camada de células parenquimáticas. Segundo Tonini et al. (2006), em sementes de S. virgata, este conjunto de células compactadas e vivas possuem atividade metabólica elevada no processo germinativo (quatro e cinco dias após a embebição) e pós-germinativo.

$\mathrm{Na}$ face mais interna das sementes de $S$. virgata, foi possível observar a camada de aleurona, que permaneceu ligada à camada de parênquimas e localizava-se entre a testa e o 
endosperma. As células deste estrato, além de possuírem paredes espessas e alta concentração de enzimas hidrolíticas digestivas, ainda compõem um conjunto de células ricas em lipídios, proteínas e corpos amiloplastos (Özbek et al., 2016). Além disso, Potomati; Buckeridge (2002), ao descreverem as sementes desta espécie, garantem que a morfologia destas seria mais similar à de Trigonella foenum-Graecum e Cyamopsis tetragonolobus, do que, por exemplo, para as sementes de Ceratonia siliqua, por não possuem uma camada de aleurona.

Matos et al. (2015) observaram que as alterações anatômicas na camada paliçádica favoreceram a germinação de sementes de Libidibia ferrea aos 20 e 40 minutos de imersão em ácido sulfúrico concentrado, onde a remoção do tegumento causada aos 40 minutos, promoveu o dobro de remoção da camada paliçádica e os maiores incrementos para porcentagem de germinação destas sementes.

Por outro lado, Alves et al. (2009) constataram que períodos prolongados de exposição da semente ao ácido sulfúrico levam a redução de vigor por provocar ruptura parcial das estruturas do tegumento das sementes. Ademais, Torkamani et al. (2013) afirmaram que decréscimos na taxa de germinação de sementes de Valeriana officinalis L. são explicadas pelos danos causados ao embrião, em função de períodos mais longos de exposição e maiores concentrações de ácido sulfúrico.

\section{CONCLUSÕES}

A aplicação do ácido sulfúrico é eficiente na superação da dormência de sementes de $S$. virgata (Cav.) Pers. Portanto, exposição das sementes ao ácido nos períodos de 30, 45 e 60 minutos aumenta a porcentagem de germinação e o surgimento de plântulas normais.

A exposição das sementes de $S$. virgata (Cav.) ao ácido sulfúrico em períodos iguais ou superiores a 120 minutos, promove a geração de novas plântulas anormais, e redução do vigor das sementes em função das alterações morfoanatômicas em todos os estratos do tegumento.

\section{AGRADECIMENTOS}

A Fundação de Amparo à Pesquisa do Estado de Alagoas (FAPEAL), pelo apoio financeiro e ao Centro de Referências em Recuperação de Áreas Degradadas do Baixo São Francisco (CRAD) pelo apoio técnico e logístico.

\section{REFERÊNCIAS}

Abreu, G. T.; Lopes, H. M.; Rossetto, C. A. V.; Germano Filho, P.; Silva. E. R. Características físicas e estrutura de sementes e morfologia de plântulas de Flemingia macrophylla (Willd) Alston. Journal of Seed Science, 34(4), 658-664, 2012. 
Alves, E. U. A.; Bruno, R. L. A.; Oliveira, A. P.; Alves, A. U.; Alves, A. U. Escarificação ácida na superação da dormência de sementes de pau ferro (Caesalpinea ferrea Mart. ex Tu. Var. leiostachya Benth.). Revista Caatinga, 22(1), 37-47, 2009.

Bewley, J. D. Seed germination and Dormancy. The Plant Cell, Wate burry-EUA, 9, 1055-1066, 1997.

Corner, E. J. H. The seeds of Dicotyledons. Cambridge University Press, Cambridge, UK, 552p. 1976.

Costa, E. S.; Santos Neto, A. L.; Costa, R. N.; Silva, J. V.; Souza, A. A.; Santos, V. R. Dormência de sementes e efeito da temperatura na germinação de sementes de mororó. Revista Ciências Agrárias, 56(1), 19-24, 2013.

Delarmelina, W. M.; Caldeira, M. V. W.; Faria, J. C. T.; Gonçalves, E. O.; Rocha, R. L. F. Different Substrates for the Production of Sesbania virgata Seedlings. Floresta e Ambiente, 21(2), 224-233, 2014.

Torkamani, M. R. D.; Abbaspour, N.; Samadi, A. Study of Two Treatments on the Germination of Valeriana officinalis L. Seeds in Two Growth Media. African Journal of Basic \& Applied Sciences, 5(5), 232-236, 2013.

Dousseau, S.; Alvarenga, A. A.; Castro, E. M.; Arantes, L. O.; Nery, F. C. Superação de dormência em sementes de Zeyheria montana Mart. Ciência e Agrotecnologia, 31(6), 1744-1748, 2007.

Ferreira, D. F. Sisvar: a Guide for its Bootstrap procedures in multiple comparisons. Ciência e Agrotecnologia, 38(2), 109-112. 2014.

Ferreira, N. R.; Franke, L. B.; Moço, M. C. C. Estudos morfo-anatômicos relacionados à dormência em sementes de Adesmia tristis Vogel (Fabaceae). Revista Brasileira de Sementes, 33(3), 447-453, 2011.

Florentino, L. A.; Moreira, F. M. S. Características simbióticas e fenotípicas de Azorhizobium doebereinerae, microssimbiote de Sesbania virgata. Revista Árvore, 33(2), 215-226, 2009.

Iganci, J. R. V.; Miotto, S. T. S. 2015. Sesbania in Lista de Espécies da Flora do Brasil. Jardim Botânico do Rio de Janeiro. Disponível em: <http://floradobrasil.jbrj.gov.br/jabot/floradobrasil/FB19125>. Acesso em: 15 dez. 2016.

Johansen, D. L. Plant microtechinique. McGraw-Hill, New York, USA, 523 p. 1940.

Labouriau, L. G. A germinação das sementes. Secretaria Geral da Organização dos Estados Americanos, Washington, USA, 174p. 1983.

Lima, C. R.; Bruno, R. D. E. L. A.; Silva, K. D. A. R. G.; Pacheco, M. V.; ALVES, E. U. Qualidade fisiológica de sementes de diferentes árvores matrizes de Poincianella pyramidalis (Tul.). Revista Ciência Agronômica, 45(2), 370-378, 2014.

Loureiro, M. B.; Teles, C. A. S.; Virgens, I. O.; Araújo, B. R. N.; Fernandez, L. G.; Castro, R. D. Aspectos morfoanatômicos e fisiológicos de sementes e plântulas de Amburana cearensis (FR. ALL.) A. C. Smith (Leguminosae papilionoideae). Revista Árvore, 37(4), 679-689, 2013.

Matos, A. C. B.; Ataíde, G. D. A M.; Lima, E.; Borges, E. E. Physiological, physical, and morphoanatomical changes in Libidibia ferrea ((Mart. ex Tul.) L.P. Queiroz) seeds after overcoming dormancy. Journal of Seed Science, 37(1), 026-032, 2015. 
Montoan, P.; Leal, H. P. S.; Marteline, M. A.; Moraes, C. P. Escarificação mecânica e química na superação de dormência de Adenanthera pavonina L. (Fabaceae: Mimosoideae). Scientia Plena, 8(5), 1-8, 2012.

Oliveira, L. M. D.; Bruno, R. D. L. A.; Alves, E. U.; Sousa, D. M. M.; Andrade, A. P. D. Tratamentos pré-germinativos em sementes de Samanea tubulosa Bentham - (Leguminoseae e Mimosoideae). Revista Árvore, 36(3), 433-440. 2012.

Özbek, F.; Büyükkartal, H. N.; Ekici, M.; Özbek, M. U.; Seed Coat Ultra structure of the Genus Astragalus L. Section Uliginosi Gray (Fabaceae). Gazi University Journal of Science, 29(2), 279283. 2016.

Potomati, A.; Buckeridge, M. S. Effect of abscisic acid on the mobilisation of galactomannan and embryo development of Sesbania virgata (Cav.) Pers. (Leguminosae - Faboideae). Revista Brasileira de Botânica, 25(3), 303-310. 2002.

Silva, A.C.; Santos, J. L.; D'arêde, L. O.; Morais, O. M.; Costa, E. M.; Silva, E. A. A. Caracterização biométrica e superação de dormência em sementes de Chloroleucon foliolosum (Benth.) G. P. Lewis. Revista Brasileira de Ciências Agrárias, 9(4), 577-582, 2014.

Tonini, P. P.; Lisboa, C. G. S.; Freschi, L.; Mercier, H.; Mazzoni-Viveiros, S. C.; Buckeridge, M. S. Effect of abscisic acid on galactomannan degradation and endo- $\beta$-mannanase activity in seeds of Sesbania virgata (Cav.) Pers. (Leguminosae). Trees, 20(6), 669-678. 2006.

Wang, X. X.; Sun H. J.; LIU, Y.; Chen, Y. T.; Feng, D. L.; LI, S. Effects of treating with concentrated sulfuric acid on the seed germination of ten Hibiscus hamabo provenance families. The journal of applied ecology, 23(11), 2968-2974. 2012.

Zucareli, V.; Amaro, A. C. E.; Silvério, E. V. Ferreira, G. Métodos de superação da dormência e temperatura na germinação de sementes de Dioclea violacea. Ciências Agrárias, 31(1), 1305-1312. 2010. 